\title{
Specific leaf metabolic changes paving the way to osmotic potential in four Quercus species in response to drought
}

\author{
Ismael Aranda ${ }^{1}$, Estrella Cadahia ${ }^{1}$, and Brígida Fernández de Simón ${ }^{1}$ \\ ${ }^{1}$ Instituto Nacional de Investigación y Tecnología Agraria y Alimentaria
}

June 12, 2020

\begin{abstract}
Osmotic adjustment is recognized as an important mechanism of maintaining turgor under water stress. However, the metabolic basis of this process has been documented in some few forest tree species. The leaf water relations of four Quercus species were studied from P-V curves in well-watered (WW) and water-stressed (WS) seedlings. Lowest values of osmotic potential at full turgor $(\Psi \pi 100)$ followed the ranking $\mathrm{Q}$. ilex $<\mathrm{Q}$. faginea $<\mathrm{Q}$. pyrenaica $<\mathrm{Q}$. petraea. The leaf osmotic potential at the turgor loss point ( $\Psi$ TLP) kept up with the patterns of the $\Psi \pi 100$ across species and treatments. The leaf metabolome pointed out to the pool of carbohydrates, some organic acids, and cyclitols as main contributors to osmotic potential. Amino-acids, although very reactive to WS particularly in Q. pyrenaica accounted quantitatively less to osmotic potential than rest of the compounds. The relevance of proto-quercitol was high as a contributor to osmotic potential regardless treatment or species. Other metabolites as quinic acid played a more relevant role in osmoregulation specifically in Q. ilex. The study shows leaf osmotic potential is underpinned by a metabolic response shaped according to phylogenetic history and ecology of the species.
\end{abstract}

\section{Hosted file}

Aranda_manuscript.doc available at https://authorea.com/users/332882/articles/459232specific-leaf-metabolic-changes-paving-the-way-to-osmotic-potential-in-four-quercusspecies-in-response-to-drought 


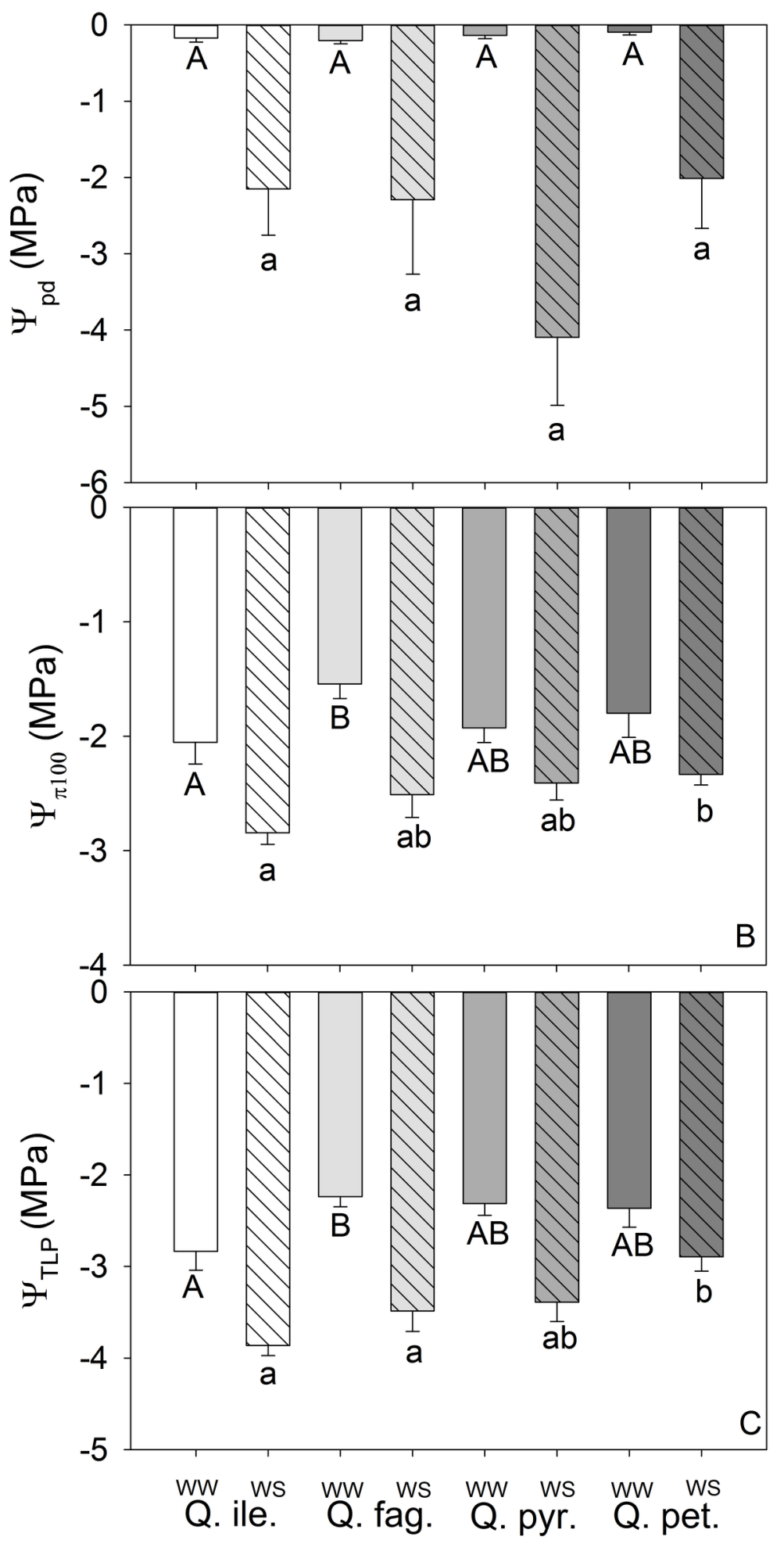



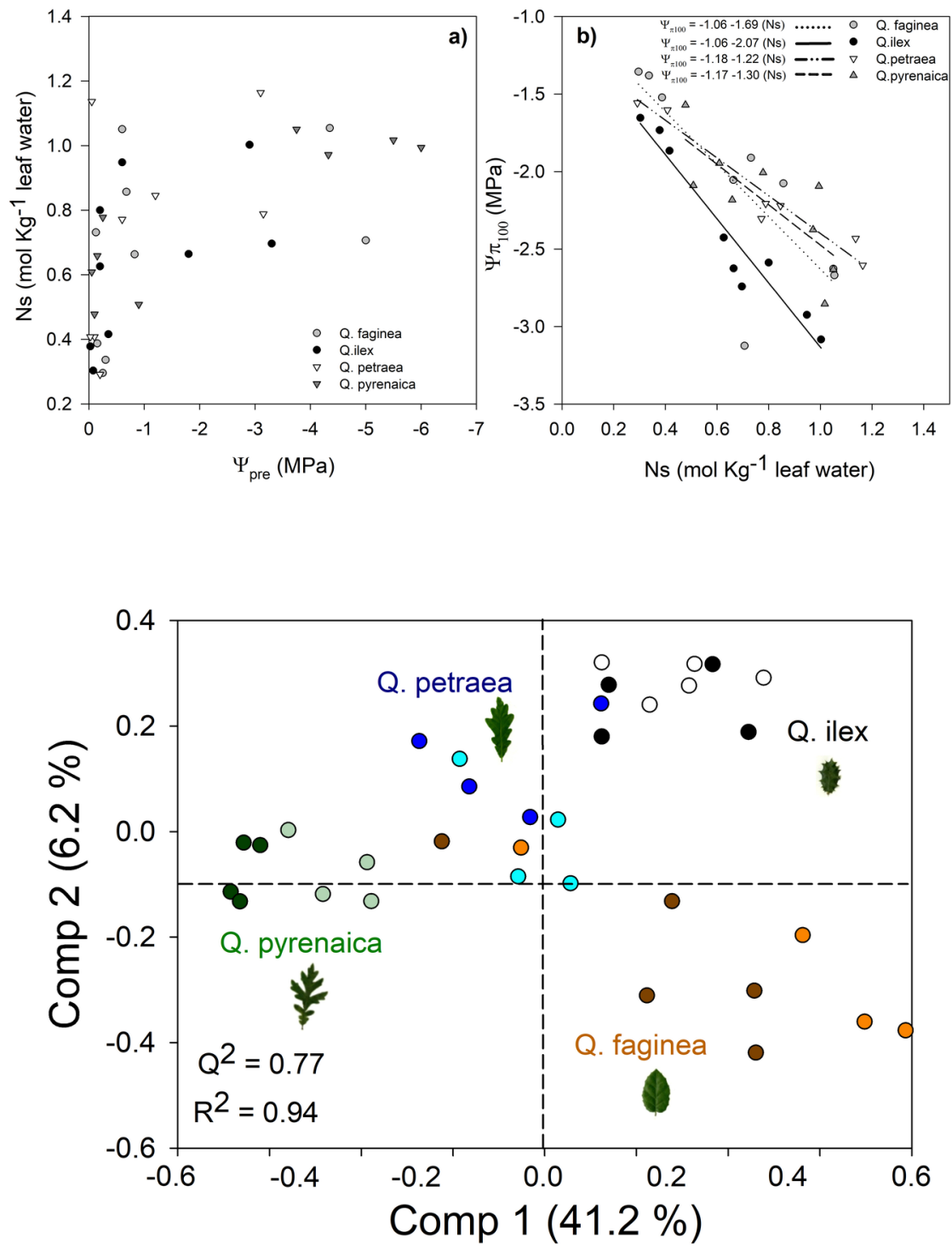

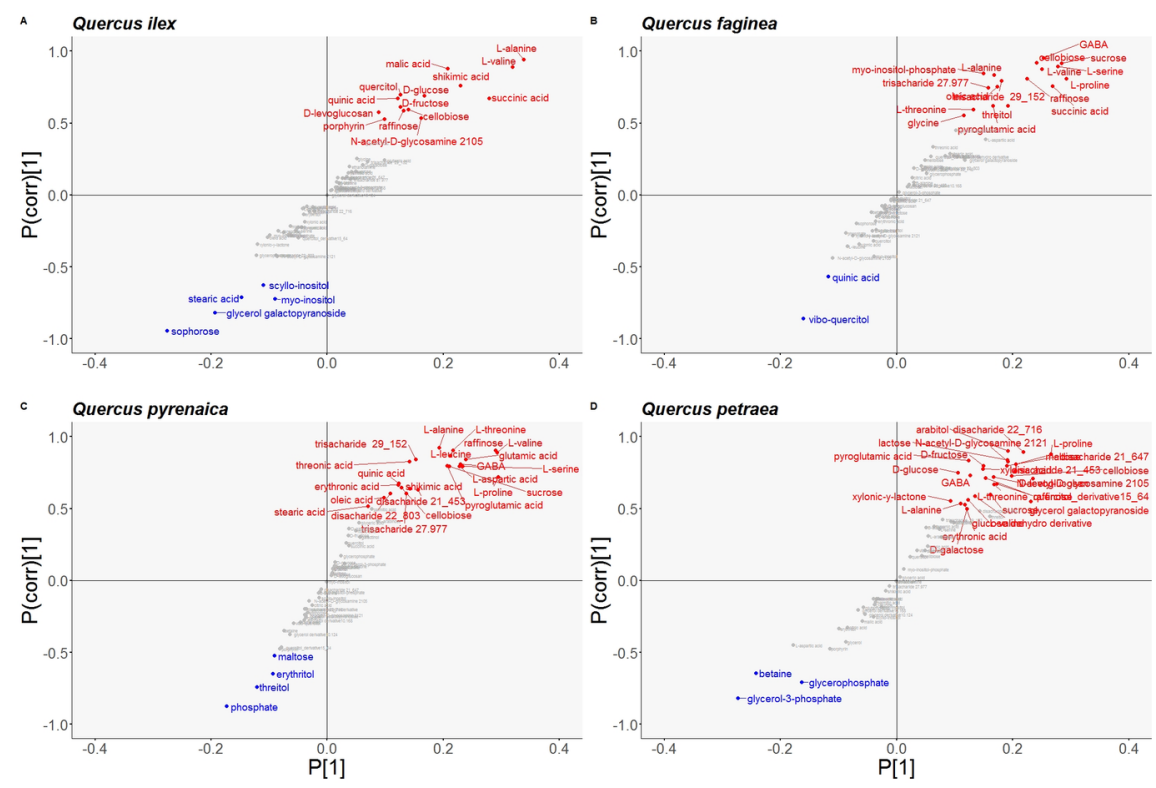

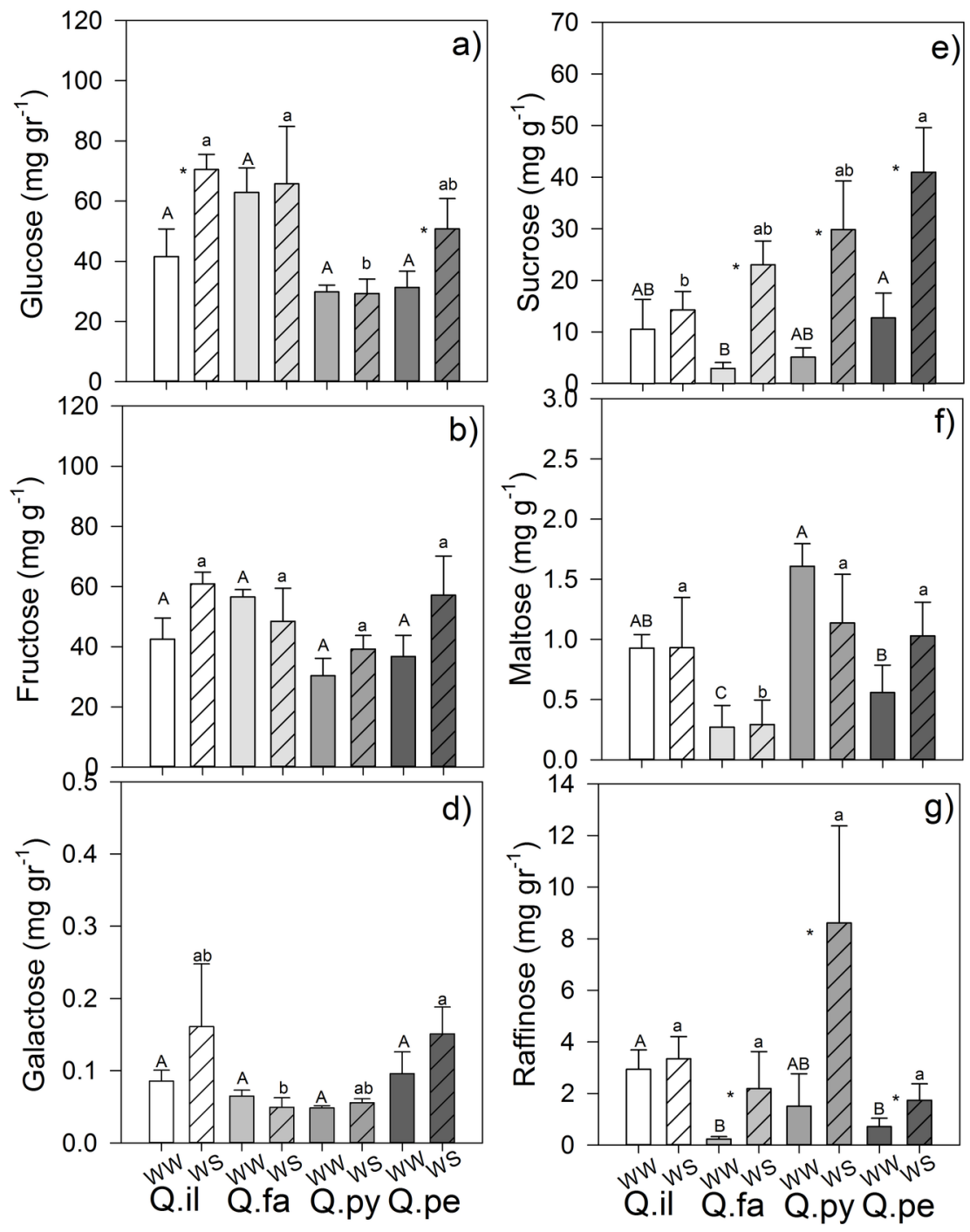

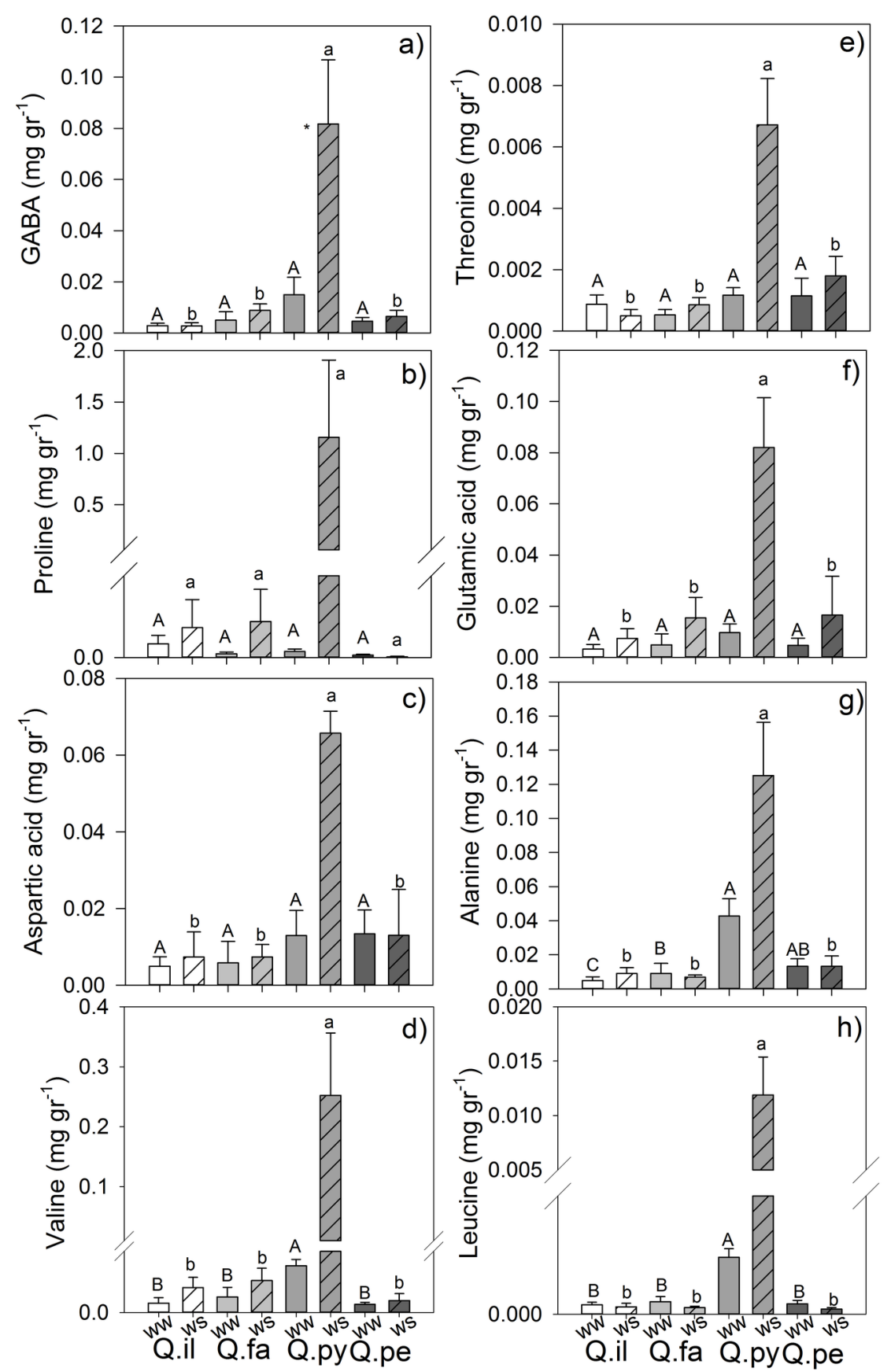

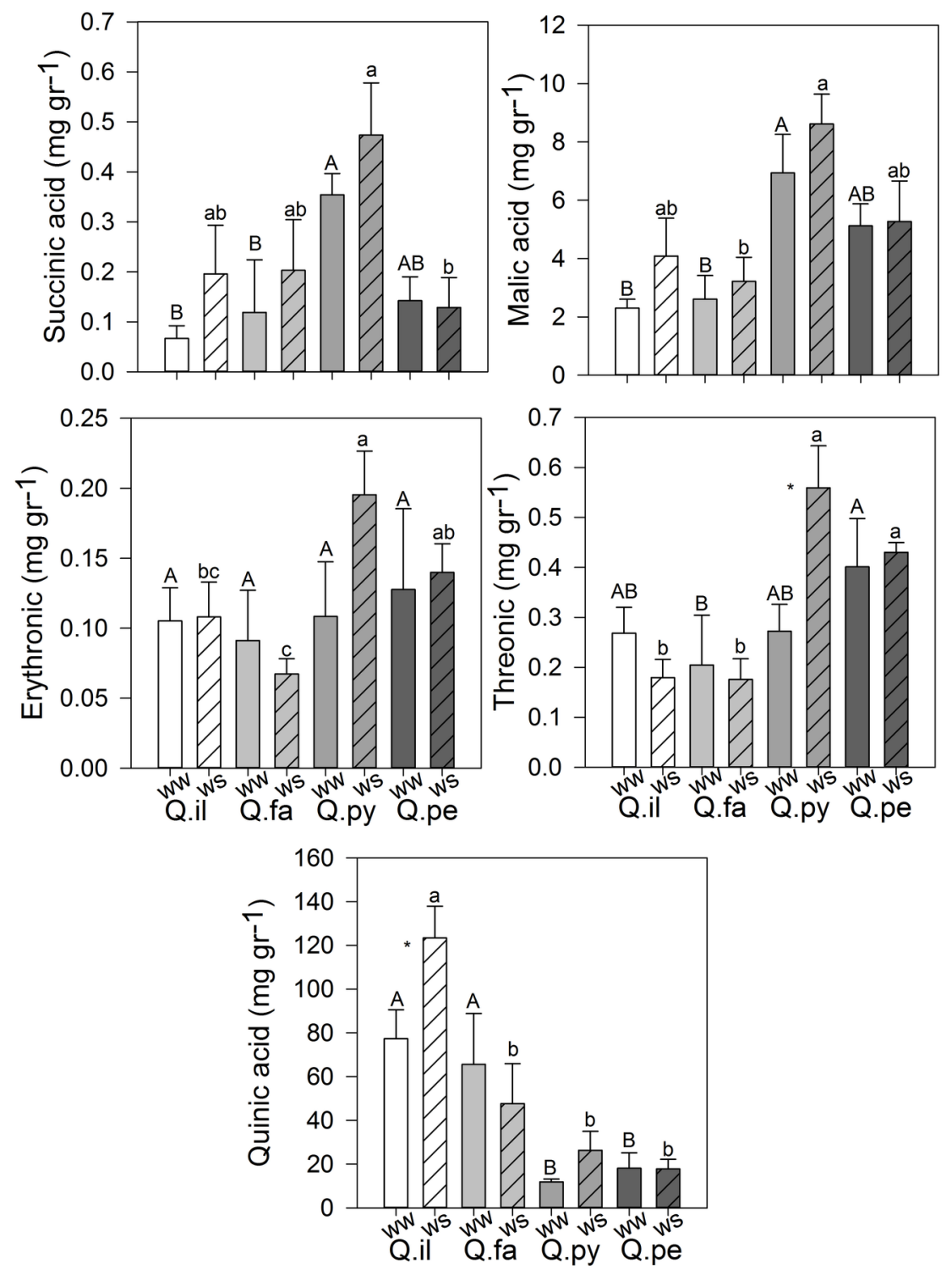


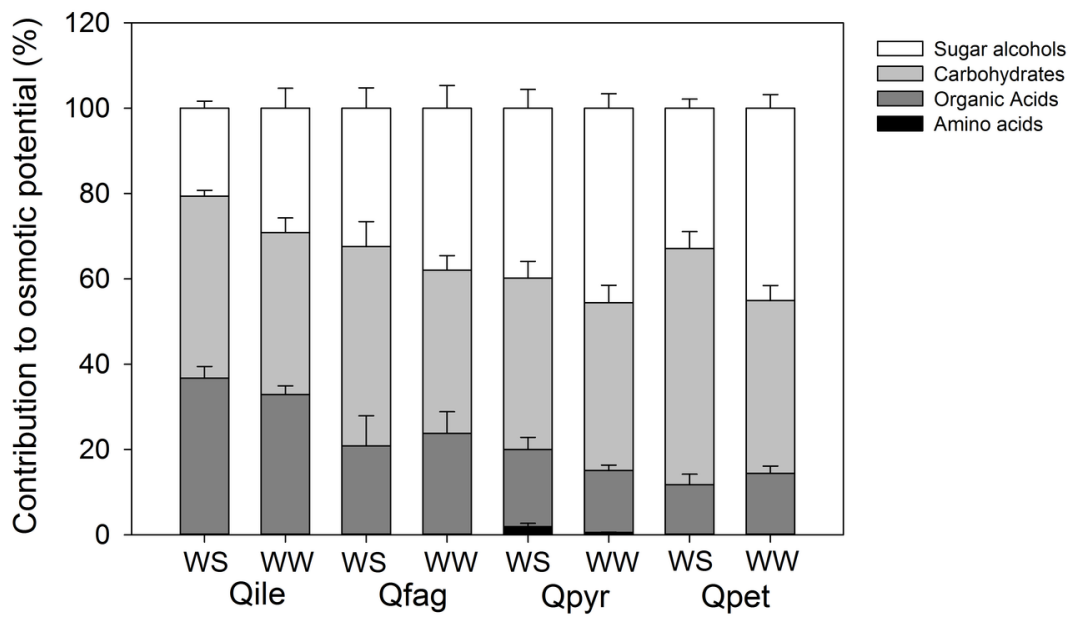

